\title{
ARAŞTIRMA / RESEARCH \\ COVID-19 pandemisinin yetişkinlerin diyet davranışları, fiziksel aktivite ve stres düzeyleri üzerine etkisi
}

Effect of COVID-19 pandemic on adults' dietary behaviors, physical activity and stress levels

\author{
Gülyeter Erdoğan Yüce1(D), Gamze Muz(D)
}

${ }^{1}$ Nevșehir Hacı Bektaş Veli Üniversitesi, Sağlık Hizmetleri MYO Sağlık Bakım Hizmetleri Bölümü, Nevşehir, Turkey ${ }^{2}$ Nevşehir Hacı Bektaş Veli Üniversitesi, Semra Vefa Küçük Sağlık Bilimleri Fakültesi, Hemşirelik Bölümü İç Hastalıkları Hemşireliği Anabilim Dalı, Nevşehir, Turkey

\section{Cukurova Medical Journal 2021;46(1):283-291}

\section{Abstract}

Purpose: The aim of this study was to investigate the change of restrictions applied in the COVID-19 pandemic in the diet behaviors, physical activities and stress levels of adults in Turkish population with this study.

Materials and Methods: This study, designed as a crosssectional type, was conducted publicly with people who are 18 years old and over this age and living in different provinces of Turkey between 9-18 June 2020. Due to the measures of the pandemic process, the data were collected by electronic survey from 579. Participant Information Form, Dietary Behavior Form, International Physical Activity Questionnaire-Short Form and a four-item form of the Perceived Stress Scale were used to collect the research data.

Results: Of the participants, $69.7 \%$ consumed their favorite foods more, $70.4 \%$ increased the frequency of snacking after meals, $74.8 \%$ increased tea and coffee consumption, $65.1 \%$ increased consumption of sugary foods such as chocolate and sweets, $68.9 \%$ increased flour and bakery products, and $67.9 \%$ increased the fruit consumption. $54.1 \%$ of the participants, $56.3 \%$ of the women and $48.1 \%$ of the men were inactive. Perceived stress level of women was higher and the difference was significant.

Conclusion: During pandemics period, that the popular foods were consumed more, nearly half of the participants in the study and more than half of the women spent the whole day in a closed environment and more than half of the participants were inactive.

Keywords: COVID-19; diet, immobilization, psychological stress, risk factors
Öz

Amaç: $\mathrm{Bu}$ çalışma ile COVID-19 pandemisi kısıtlamalarında Türk toplumundaki yetişkinlerin diyet davranışları, fiziksel aktivite ve stres düzeylerindeki değișimin araştırılması amaçlanmıștır.

Gereç ve Yöntem: Kesitsel tipte tasarlanan bu çalışma, 918 Haziran 2020 tarihleri arasında Türkiye'nin farklı illerinde yaşayan 18 yaş ve üzerindeki herkese açık olarak yapilmıştır. Pandemi süreci tedbirleri nedeniyle veriler elektronik anketlerle toplanmıştır. Veri toplama araçlarını dolduran 579 kiși araștırmanın örneklemini olușturmuștur. Araştırma verilerinin toplanmasında tanıtıcı bilgi formu, diyet davranışı formu, Uluslararası Fiziksel Aktivite Anketi- Kısa Formu ve Algılanan Stres Ölçeğinin dört maddelik formu kullanılmıştır.

Bulgular: Katılımcıların, \%69.7’sinin sevdiği gıdaları daha fazla tükettiği, \%70.4'ünün yemeklerden sonra atıştırma sıklığının arttı̆̆ı, \%74.8'inin çay ve kahve, \%65.1'inin çikolata ve tatlı gibi şekerli gıda, \%68.9'unun un ve unlu mamul ve \%67.9'unun meyve tüketiminin arttı̆̆1 belirlenmiştir. Katılımcıların \%54.1'inin, kadınların \%56.3'ünün, erkeklerin ise \%48.1'inin inaktif olduğu belirlenmiştir. Kadınların algılanan stres seviyesinin daha yüksek olduğu ve farkın anlamlı olduğu bulunmuştur .

Sonuç: Kısıtlamalar süresince sevilen gıdaların daha fazla tüketildiği, çalışmaya katılanların yarısına yakının, kadınların ise yarısından fazlasının tüm günü kapalı ortamda geçirdiği ve katılımcıların yarısından fazlasının inaktif olduğu bulunmuştur.

Anahtar kelimeler: COVID-19; diyet; hareketsizlik, psikolojik stres; risk faktörleri 


\section{GİRİŞ}

Koronavirüsler (CoV), fenotipik ve genotipik olarak çeşitlilik gösteren Orta Doğu Solunum Sendromu (MERS-CoV) ve Şiddetli Akut Solunum Sendromu (SARS-CoV) gibi daha ciddi hastalıklara neden olan geniş bir virüs ailesidir ${ }^{1,2}$. Yeni Koronavirüs Hastalığı (COVID-19), ilk olarak Çin'in Vuhan Eyaleti'nde Aralık ayının sonlarında solunum yolu belirtileri (ateş, öksürük, nefes darlı̆̆1) ile gelişen bir grup hastada yapılan araştırmalar sonucunda Ocak 2020'de tanımlanan bir virüstür ${ }^{1,2}$. COVID-19 Çin'den sonra hızlı bir yayılım göstererek küresel bir kriz haline gelmiştir. Dünya Sağlık Örgütü (DSÖ) Mart 2020 itibariyle, pandemi olarak duyurmuştur ${ }^{2,3}$. COVID-19 pandemisinin tüm dünyada sağlık, sosyal ve ekonomik alanlarda çok geniş etkileri olmuştur. COVID-19 pandemisi karşısında, halk sağlı̆̆1 önerileri ve hükümet önlemleri daha fazla evde kalmayı, sosyal izolasyonu ve karantina gibi insanların serbest dolaşımı ile ilgili kısıtlamaları zorunlu kılmıştır. Bazı ülkelerde açık hava etkinliklerine katılma süresini sınırlayan veya açık hava etkinliklerini tamamen kısıtlayan yasaklar getirilmiştir ${ }^{4}$. Türkiye'de mart ayında ilk vakanın görülmesi ile birlikte COVID-19 virüsünün yayılmasını kontrol altına almak için diğer ülkelerde olduğu gibi sıkı tedbirler uygulanmaya başlanmıştır ${ }^{1}$.

$\mathrm{Bu}$ tedbirler enfeksiyon oranını azaltmaya yardımcı olurken nüfusun alışkanlıklarında ve yaşam tarzlarında da ani ve radikal bir değişime neden olmuştur ${ }^{4,5}$. Fiziksel mesafe ve sosyal izolasyon insanların yaşamlarını, özellikle yeme alışkanlıklarını ve günlük fiziksel aktivitelerini etkilemiştir. Sosyal alandaki kısıtlamalar nedeniyle evde kalmak, dijital eğitim, evden çalışma, açık havada ve spor salonunda fiziksel aktivitenin sinırlandırılması normal günlük aktivitelere katılımı kısıtlamıştır ${ }^{4,5-9}$. Uzun süre evde kalma gerekliliği insanların taze gıdalara erişimin sınırlı olmasına, standart yaşam koşullarına kıyasla tuz, şeker, trans yağ içeriği ve kalorisi daha yüksek uzun raf ömrüne sahip ve daha az besleyici gidaları tüketmeye yönelmesi riskini artırmıştır-7,10,11. Bu durum, sağllklı ve çeşitli bir diyetin ve düzenli bir fiziksel aktivitenin sürdürülmesini de engellemiştir. Sosyal etkileşim kurmaya alışkın olan insanların arkadaş ve aileleri ile mesafelerini korumak zorunda kalmaları, aniden daha fazla veya tamamen yalnız kalmaları, kısıtlamalar nedeniyle günlük rutinlerinin kesintiye uğramas1, medyadan sürekli olarak COVID19 ile ilgili haberlerin duyulması veya okuması anksiyete ve stresi artırmıştır 5,12-14.
Fiziksel inaktivite, sağlıksız beslenme ve kontrol altına alınamayan stresin fiziksel ve zihinsel sağlığ1 etkileyerek yaşam kalitesi üzerinde olumsuz etkilere yol açtığ1; küresel olarak kardiyovasküler olaylar, obezite ve diyabet başta olmak üzere kronik hastalık morbiditesi için en önemli risk faktörleri arasında yer aldığ1 bilinmektedir ${ }^{15-17}$. Bununla birlikte, obez ve kronik hastalığa sahip olan kişilerin COVID-19'dan ölme riskinin daha yüksek olduğu bilinmektedir. Bu sebeple kronik hastalıkların önlenmesi ve kontrolü için, bugün ve gelecekteki halk sağlığında tehdit oluşturabilecek durumlara hazırlıklı olmak bir gerekliliktir. Yaşadığımız pandemi süreci gibi toplumun yaşamını etkiyen süreçlerde toplumun sağlıklı bir şekilde baş etmesini sağlayacak ve sekonder hastalık riskini azaltacak uygun tedbirler alabilmek için bu süreçlerde meydana gelen yaşam tarzı değişikliklerini ve etkilerini araştırmak önemlidir. Çalışmalar hastalık kontrolü için alınan zorunlu tedbirlerin sağlık üzerindeki potansiyel faydalarının yanı sıra kronik hastalık riski ve ruh sağlığına etkisi gibi olası uzun vadeli olumsuz etkilerinin de dikkatle değerlendirilmesi gerektiğini vurgulamaktadır ${ }^{11,18,19}$. Ancak pandemi ile mücadele için uygulanan tedbirlerin fiziksel aktivite, diyet davranışları ve stres düzeyi üzerindeki etkisini değerlendirmek için yapılan çalışmaların sayısı sınırlıdır. Bu süreçte nüfusun farklı hedef gruplarının sağlık durumunun desteklenmesi ve yaşam tarzı değişikliklerine uygun önerilerin geliştirilmesi için bir temel oluşturmak önemlidir. Bu sebeple bu çalışma ile COVID-19 pandemisi kısıtlamalarında Türk toplumundaki yetişkinlerin diyet davranışları, fiziksel aktivite ve stres düzeylerindeki değişimin araştırılması amaçlanmıştır.

$\mathrm{Bu}$ amaç doğrultusunda çalışmada 'COVID- 19 pandemisi kısıtlamalarında yetişkinlerin günlük yaşamlarında değişim var midır?', 'COVID- 19 pandemisi kısıtlamalarında yetişkinlerin diyet davranışlarında değişim var mıdır?', 'COVID- 19 pandemisi kısıtlamalarında yetişkinlerin fiziksel aktivite düzeyi nedir?', 'COVID- 19 pandemisi kısıtlamalarında yetişkinlerin stres düzeyi nedir?’ ve 'COVID- 19 pandemisi kisitlamalarında kadınların ve erkeklerin diyet davranışları, fiziksel aktivite ve stres düzeyleri arasında fark var mıdır?' sorularına yanıt aranmiştır.

\section{GEREÇ VE YÖNTEM}

$\mathrm{Bu}$ çalışma, COVID-19 pandemisi kısıtlamalarında yetişkinlerin diyet davranışları, fiziksel aktivite ve stres düzeylerinde meydana gelen değişimin 
değerlendirilmesi amaciyla kesitsel tipte tasarlanmıştır. Türkiye'de ilk yeni tip koronavirüs vakas1 11 Mart 2020'de görülmüștür. İlk vakanın ilan edilmesinden sonra sosyal izolasyon tedbirleri başlamıştır. Tedbirler kapsamında ilk dönem 1 Haziran 2020 tarihinde sona ermiş ve kontrollü sosyal hayat dönemine geçilmiştir. Çalışma ilk dönem tedbirleri kaldırıldıktan sonra 9 - 18 Haziran 2020 tarihleri arasında yürütülmüştür. Türkiye'nin farklı illerinde yaşayan 18 yaş ve üzerindeki herkese açık olarak yapılmıştır. Pandemi süreci nedeniyle veriler; Google Formlar aracıllğıyla oluşturulan elektronik anketler yoluyla toplanmıştır. Katılımcılar çalışmaya sosyal medya platformlarından davet edilmiştir. Bu yolla ulaşılan, araştırmaya katılmaya gönüllü olan, veri toplama araçlarını dolduran, 18 yaş ve üzerinde olan 579 birey araştırmanın örneklemini oluşturmuştur.

Çalışmaya katılmayı kabul eden katılımcılardan, çevrimiçi anketin başlangıcında bilgilendirilmiş onamları alınmıştır. Çalışma Helsinki Bildirgesi'ne göre sürdürülmüştür. Çalışmanın yapılması için Sağlık Bakanlığ1 Bilimsel Araştırma Komisyonu'ndan gerekli izinler alınmıştır (2020-05-28T21_13_21). Ayrıca çalışma protokolü Nevşehir Hacı Bektaş Veli Üniversitesi Etik Komitesi tarafından onaylanmıştır (Tarih:08.06.2020, Karar No: 2020.12.127).

\section{Veri toplama araçları}

Araştırma verilerinin toplanmasında Tanıtıcı Bilgi Formu, Diyet Davranışı Formu, Uluslararası Fiziksel Aktivite Anketi- K1sa Formu ve Alg1lanan Stres Ölçeğinin dört maddelik formu kullanılmıştır.

\section{Tanıtıc1 Bilgi Formu}

Araştırmacılar tarafindan oluşturulan bu form, katılımcıların yaşı, cinsiyeti, medeni durumu, eğitim durumu ve meslek gibi sosyo-demografik özellikler ile ilgili soruların yanında; boy, kilo, kısıtlamalar süresince kilo değişimi, kapalı alanlarda günlük olarak geçirilen süre, uyku değişimi, günlük uyku ve ekran süresi ile ilgili 11 soruyu içermektedir.

\section{Diyet Davranışı Formu}

Bu form katılımcıların diyetlerinde tedbirler süresince meydana gelen değişimi tanımlamak için araştırmacılar tarafından ilgili literatür dikkate alınarak oluşturulmuştur ${ }^{5,10-12,20}$. Form her bir öğünde tüketilen gida miktarlarındaki, sevilen gidaların tüketimindeki ve atıştırma sıklığındaki değişim, kırmızı et, sebze, meyve, un ve unlu mamuller, cips, çerez, çikolata ve tatlı gibi yiyecekler, şekerli ve gazlı içecekler, çay ve kahve tüketimi gibi diyet davranışlarındaki değişimi gösteren 13 soruyu içermektedir.

\section{Uluslararası Fiziksel Aktivite Anketi - Kisa Form (UFAA- KF)}

Uluslararas1 Fiziksel Aktivite Anketi (UFAA-KF) 1565 yaş aralığındaki katılımcıların fiziksel aktivite düzeylerini belirlemek amacıyla Craig ve arkadaşları tarafindan geliştirilmiştir ${ }^{21}$. Anketin Türkiye'deki geçerlik ve güvenilirlik çalışması Öztürk tarafindan yapılmıştır ${ }^{22}$. Anket son 1 haftadaki fiziksel aktivite düzeyini değerlendirmektedir. Yedi sorudan oluşan form oturma, yürüme, orta düzeyde şiddetli aktiviteler ve şiddetli aktivitelerde harcanan zaman hakkında bilgi sağlamaktadır.

Ankete göre bütün aktivitelerin değerlendirilmesinde her bir aktivitenin tek seferde en az 10 dakika yapıllyor olması ölçüt kabul edilmektedir. Fiziksel aktivite düzeyini belirlemede her bir fiziksel aktivite türü için dakika, gün ve metabolik eşdeğerlilik (MET) çarpılarak MET dakika/hafta olarak bir skor elde edilmektedir. Fiziksel aktivite düzeyleri, fiziksel olarak aktif değil/inaktif (<600 MET dk/hafta), düşük fiziksel aktivite düzeyi/minimal aktif (600-3000 METdk/hafta) ve yeterli fiziksel aktivite düzeyi/aktif (>3000 METdk/hafta) şeklinde sınıflandırılmaktadır. Anketin Türkçe formunun Cronbach alfa katsayı 0.69 olarak bildirilmiştir ${ }^{22}$.

\section{Algılanan Stres Ölçeği (ASÖ)}

Algılanan Stres Ölçeği (ASÖ), Cohen, Kamarck ve Mermelstein tarafindan geliştirilmiştir ${ }^{23}$. ASÖ kişinin hayatındaki birtakım durumların ne derece stresli algılandığını ölçmek için tasarlanmıştır. Ölçeğin Türkçe geçerlik ve güvenirliği Eskin ve arkadaşları tarafindan yapılmıştır ${ }^{24}$. Ölçekteki her madde "Hiçbir zaman (0)" ile "Çok sık (4)" arasında değişen 5'li Likert tipte değerlendirmektedir.

Ölçeğin 14 maddelik uzun formunun yanı sıra ASÖ’nün 10 ve 4 maddelik olmak üzere iki formu daha bulunmaktadır. Bu çalışmada dört maddelik olan form kullanılmıştır. Uzun formun 2, 6, 7, 14 numaralı maddelerinden oluşan ASÖ-4'ün 6 ve 7 numaralı maddeleri tersten puanlanmaktadır. Ölçeğin toplam puanı 0 ile 16 arasında değişmektedir. Yüksek puanlar kişinin stres algısının yüksek olduğuna göstermektedir. Ölçeğin Türkçe geçerlik ve güvenirlik çalışmasında ASÖ-4’ün Cronbach alfa katsayısı 0,66 olarak belirlenmiştir ${ }^{24}$. 


\section{İstatistiksel analiz}

Verilerin istatistiksel analizinde SPSS 22.0 (Statistical Package for Social Sciences) paket program1 kullanılmıştır. Verilerin dağılımı kategorik değişkenler için sayı (n) ve yüzde (\%), sayısal değişkenler için ortalama (ort) ve standart sapma (ss) ile gösterilmiştir. Verilerin normal dağılıma uygunluğunu skewness ve kurtosis değerleri ile değerlendirilmiştir.

Fiziksel aktivite düzeyi, günlük yaşamda ve diyet davranışında meydana gelen değişimi içeren kategorik değişkenlerin cinsiyete göre karşılaştırılmasında kikare testi, günlük oturularak geçirilen süre, toplam fiziksel aktivite MET ve algilanan stres düzeylerinin cinsiyete göre karşılaştırılmasında bağımsız örneklerde $\mathrm{t}$ testi kullanılmıştır. $\mathrm{p}<0.05$ değeri istatistiksel olarak anlamlı kabul edilmiştir.

\section{BULGULAR}

Katılımcların sosyo-demografik ve bireysel özellikleri Tablo 1'de görülmektedir. Buna göre katıllımciların \%72.7'sinin kadın, \%51.8'inin bekar, \%87.9'unun üniversite mezunu, \%33.5'inin öğrenci olduğu belirlenmiștir. Katıllımcıların yaș ortalamasının 30.43 \pm 9.36 , vücut kitle indeksi ortalamasinın $24.39 \pm 4.35$ olduğu bulunmuştur.

Tablo 1- Yetişkinlerin Sosyo-Demografik ve Bireysel Özelliklerine Göre Dağılımı

\begin{tabular}{|c|c|c|}
\hline+2 & $\mathrm{n}$ & $\%$ \\
\hline \multicolumn{3}{|l|}{ Cinsiyet } \\
\hline Kadin & 421 & 72.7 \\
\hline Erkek & 158 & 27.3 \\
\hline \multicolumn{3}{|l|}{ Medeni Durum } \\
\hline Evli & 279 & 48.2 \\
\hline Bekar & 300 & 51.8 \\
\hline \multicolumn{3}{|l|}{ Eğitim Durumu } \\
\hline İlköğretim & 32 & 5.5 \\
\hline Lise & 38 & 6.6 \\
\hline Üniversite & 509 & 87.9 \\
\hline \multicolumn{3}{|l|}{ Meslek } \\
\hline Öğrenci & 194 & 33.5 \\
\hline Memur & 182 & 31.4 \\
\hline İșçi & 16 & 2.8 \\
\hline Ev hanımı & 50 & 8.6 \\
\hline Çalışmıyor & 26 & 4.5 \\
\hline Diğer & 111 & 19.2 \\
\hline Yaş (y1l) (ort $\pm \mathrm{ss}$ ) & \multicolumn{2}{|c|}{$30.43 \pm 9.36$} \\
\hline Kilo $(\mathrm{kg})($ ort $\pm \mathrm{ss})$ & \multicolumn{2}{|c|}{$68.41 \pm 14.34$} \\
\hline Boy $(\mathrm{cm})($ ort $\pm \mathrm{ss})$ & \multicolumn{2}{|c|}{$167.18 \pm 8.30$} \\
\hline Vücut Kitle İndeksi (VKI) $\left(\mathrm{kg} / \mathrm{m}^{2}\right)$ (ort $\left.\pm \mathrm{ss}\right)$ & \multicolumn{2}{|c|}{$24.39 \pm 4.35$} \\
\hline
\end{tabular}

COVID-19 kısıtlamalarında yetişkinlerin günlük yaşamlarında meydana gelen değişim Tablo 2'de görülmektedir. Bu süreçte katılımcıların \%49.8'inin 21-24 saat süre ile kapalı alanda vakit geçirdiği, \%47.8'inin kilo aldığı, \%32.0'ının 4-6 saat ekran süresi olduğu, \%51.8'inin günlük 8-10 saat uyku süresi olduğu ve \%43.5'inin uyku süresinin arttı̆̆1 belirlenmiștir. Kısıtlamalar süresince kadınların erkeklere göre kapalı alanlarda daha fazla zaman geçirdiği ( $\mathrm{p}>0.001)$ ve erkeklerin kadınlara oranla daha fazla kilo alımı bildirdiği $(\mathrm{p}<0.05)$ bulunmuştur.

COVID-19 kısıtlamalarında yetişkinlerin diyet alışkanlıklarında meydana gelen değişim Tablo 3'te görülmektedir. Bu süreçte katılımcıların, \%69.7’sinin sevdiği g1daları daha fazla tükettiği, \%70.4'ünün yemeklerden sonra bir şey atıştırma sıklığının arttığ1, \%55.4'ünün cips, çerez gibi gıdaları daha sık tükettiği, $\% 74.8$ 'inin çay ve kahve tüketiminin arttığ 1 , $\% 65.1$ 'inin çikolata ve tatlı gibi şekerli gidaları daha fazla tükettiği, \%68.9'unun un ve unlu mamul tüketiminin arttığ1 ve \%67.9'unun meyve tüketiminin arttığı belirlenmiştir. Kadınlarda erkeklere oranla öğle yemeğinde tüketilen besin miktarının $(p<0.05)$, çikolata, tatlı gibi şekerli gidalar $(p<0.001)$, un ve unlu mamul $(\mathrm{p}<0.05)$, sebze $(\mathrm{p}<0.05)$ tüketiminin anlamlı olarak yüksek olduğu bulunmuştur. Erkeklerde ise kadınlara oranla sevdiği gıdaları tüketme $(p<0.05)$, yemeklerden sonra bir şey 
atıştırma $(\mathrm{p}<0.05)$ sıklığ1 ve çay, kahve tüketimindeki $(p<0.05)$ artışın daha yüksek olduğu belirlenmiştir.

COVID-19 salgını sürecinde yetişkinlerin fiziksel aktivite ve algilanan stres düzeyleri Tablo 4'te görülmektedir. Bu süreçte katılımcıların \%54.1'inin, kadınların \%56.3'ünün erkeklerin ise \%48.1'inin inaktif olduğu belirlenmiştir. Kadın ve erkeklerin fiziksel aktivite düzeyleri arasında farklılık bulunmamıştır. ( $p>0.05)$. Günlük olarak oturularak geçirilen sürenin kadınlarda 6.36 \pm 4.20, erkeklerde
$6.87 \pm 4.49$ saat, toplam fiziksel aktivite MET

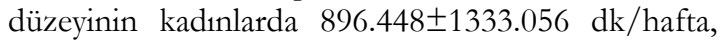
erkeklerde $1015.505 \pm 1246.956 \mathrm{dk} /$ hafta olduğu belirlenmiştir. Kadın ve erkekler arasında günlük olarak oturularak geçirilen süre ve toplam fiziksel aktivite MET düzeyi açısından fark saptanmamıştır ( $>$ $>0.05)$. Alg1lanan stres düzeyinin toplamda 8.12 \pm 2.65 , kadınlarda $8.41 \pm 2.66$ ve erkelerde $7.36 \pm 2.45$ olduğu bulunmuştur. Kadınların algılanan stres seviyesinin daha yüksek olduğu ve farkın anlamlı olduğu belirlenmiştir $(\mathrm{p}<0.001)$.

Tablo 2- COVID-19 kısıtlamaları sürecinde yetişkinlerin günlük yaşamlarında meydana gelen değişimin cinsiyetlere göre dağılımı

\begin{tabular}{|c|c|c|c|c|c|c|c|}
\hline \multirow[t]{2}{*}{$\begin{array}{l}\text { Günlük Yaşamda Meydana Gelen } \\
\text { Değişim }\end{array}$} & \multicolumn{2}{|c|}{$\begin{array}{l}\text { Toplam } \\
(\mathrm{n}=579)\end{array}$} & \multicolumn{2}{|c|}{$\begin{array}{c}\text { Kadın } \\
(\mathrm{n}=421)\end{array}$} & \multicolumn{2}{|c|}{$\begin{array}{c}\text { Erkek } \\
(\mathrm{n}=158)\end{array}$} & \multirow[t]{2}{*}{$\mathbf{p}$} \\
\hline & $\mathrm{n}$ & $\%$ & $\mathrm{n}$ & $\%$ & $\mathrm{n}$ & $\%$ & \\
\hline \multicolumn{8}{|c|}{ Kısıtlamalar Süresince Kapalı Alanda Geçen Süre } \\
\hline 8-12 saat & 74 & 12.8 & 41 & 9.7 & 33 & 20.9 & \multirow[t]{4}{*}{$<0.001$} \\
\hline 13-16 saat & 67 & 11.6 & 32 & 7.6 & 35 & 22.2 & \\
\hline $17-20$ saat & 151 & 26.1 & 110 & 26.1 & 41 & 25.9 & \\
\hline $21-24$ saat & 287 & 49.6 & 238 & 56.5 & 49 & 31.0 & \\
\hline \multicolumn{8}{|l|}{ Kısıtlamalar Süresince Kiloda Değişim } \\
\hline Kilo alımı & 277 & 47.8 & 197 & 46.8 & 80 & 50.6 & \multirow[t]{3}{*}{0.020} \\
\hline Kilo kayb1 & 82 & 14.2 & 70 & 16.6 & 12 & 7.6 & \\
\hline Kiloda değişim yok & 220 & 38.0 & 154 & 36.6 & 66 & 41.8 & \\
\hline \multicolumn{8}{|c|}{ Kısıtlamalar Süresince Günlük Ortalama Ekran Süresi } \\
\hline 1 saatten az & 23 & 4.0 & 21 & 5.0 & 2 & 1.3 & \multirow[t]{5}{*}{0.130} \\
\hline $1-3$ saat & 142 & 24.5 & 103 & 24.5 & 39 & 24.7 & \\
\hline 4-6 saat & 185 & 32.0 & 140 & 33.3 & 45 & 28.5 & \\
\hline 7-9 saat & 133 & 23.0 & 93 & 22.1 & 40 & 25.3 & \\
\hline 10 saat ve üzeri & 96 & 16.6 & 64 & 15.2 & 32 & 20.3 & \\
\hline \multicolumn{8}{|c|}{ Kısıtlamalar Süresince Günlük Uyku Süresi } \\
\hline 5 saatten az & 30 & 5.2 & 24 & 5.7 & 6 & 3.8 & \multirow[t]{4}{*}{0.390} \\
\hline 5-7 saat & 211 & 36.4 & 148 & 35.2 & 63 & 39.9 & \\
\hline $8-10$ saat & 300 & 51.8 & 218 & 51.8 & 82 & 51.9 & \\
\hline 10 saat ve üzeri & 38 & 6.6 & 31 & 7.4 & 7 & 4.4 & \\
\hline \multicolumn{8}{|l|}{ Kısıtlamalar Süresince Uykuda Değişimi } \\
\hline Uyku sürem artt1 & 252 & 43.5 & 189 & 44.9 & 63 & 39.9 & \multirow[t]{3}{*}{0.309} \\
\hline Uyku sürem azaldı & 107 & 18.5 & 80 & 19.0 & 27 & 17.1 & \\
\hline Uyku süremde değişim olmadı & 220 & 38.0 & 152 & 36.1 & 68 & 43.0 & \\
\hline
\end{tabular}


Tablo 3- COVID-19 kısıtlamaları sürecinde yetişkinlerin diyet davranışlarında meydana gelen değişimin cinsiyetlere göre dağılımı

\begin{tabular}{|c|c|c|c|c|c|c|c|c|c|c|c|c|c|}
\hline \multirow[t]{3}{*}{ Diyet Davranış1 } & \multicolumn{4}{|c|}{$\begin{array}{l}\text { Toplam } \\
(\mathrm{n}=579)\end{array}$} & \multicolumn{4}{|c|}{$\begin{array}{l}\text { Kadın } \\
(n=421)\end{array}$} & \multicolumn{4}{|c|}{$\begin{array}{c}\text { Erkek } \\
(n=158)\end{array}$} & \multirow[t]{3}{*}{$\mathrm{p}$} \\
\hline & \multicolumn{2}{|c|}{ Evet } & \multicolumn{2}{|c|}{ Hayır } & \multicolumn{2}{|c|}{ Evet } & \multicolumn{2}{|c|}{ Hayır } & \multicolumn{2}{|c|}{ Evet } & \multicolumn{2}{|c|}{ Hayır } & \\
\hline & $\mathrm{n}$ & $\%$ & $\mathrm{n}$ & $\%$ & $\mathrm{n}$ & $\%$ & $\mathrm{n}$ & $\%$ & $\mathrm{n}$ & $\%$ & $\mathrm{n}$ & $\%$ & \\
\hline $\begin{array}{l}\text { Sabah kahvaltısında } \\
\text { tükettiğim besin } \\
\text { miktarı arttı }\end{array}$ & 275 & 47.5 & 304 & 52.5 & 213 & 50.6 & 208 & 49.4 & 62 & 39.2 & 96 & 60.8 & 0.080 \\
\hline $\begin{array}{l}\text { Öğle yemeğinde } \\
\text { tükettiğim besin } \\
\text { miktarı arttı }\end{array}$ & 233 & 40.2 & 346 & 59.8 & 182 & 43.2 & 239 & 56.8 & 51 & 32.3 & $\begin{array}{c}10 \\
7\end{array}$ & 67.7 & 0.040 \\
\hline $\begin{array}{l}\text { Akşam yemeğinde } \\
\text { tükettiğim besin } \\
\text { miktarı arttı }\end{array}$ & 311 & 53.7 & 268 & 46.3 & 232 & 55.1 & 189 & 44.9 & 79 & 50.0 & 79 & 50.0 & 0.226 \\
\hline $\begin{array}{l}\text { Sevdiğim gidaları } \\
\text { daha fazla tükettim }\end{array}$ & 403 & 69.6 & 176 & 30.4 & 297 & 70.5 & 124 & 29.5 & 106 & 77.1 & 52 & 32.9 & 0.012 \\
\hline $\begin{array}{l}\text { Yemeklerden sonra } \\
\text { bir şeyler atıștırma } \\
\text { sıklığım arttı }\end{array}$ & 423 & 70.4 & 156 & 27.0 & 318 & 75.5 & 103 & 24.5 & 105 & 66.5 & 53 & 33.5 & 0.004 \\
\hline $\begin{array}{l}\text { Cips ve çerez gibi } \\
\text { gidaları da fazla } \\
\text { tükettim } \\
\end{array}$ & 321 & 55.4 & 258 & 44.6 & 238 & 56.5 & 183 & 43.5 & 83 & 52.5 & 75 & 47.5 & 0.349 \\
\hline $\begin{array}{l}\text { Çay ve kahve } \\
\text { tüketimim arttı }\end{array}$ & 433 & 74.8 & 146 & 25.2 & 322 & 66.5 & 99 & 23.5 & 111 & 70.3 & 47 & 29.7 & 0.002 \\
\hline $\begin{array}{l}\text { Şekerli ve gazlı } \\
\text { içecekleri daha fazla } \\
\text { tükettim }\end{array}$ & 217 & 37.5 & 362 & 62.5 & 159 & 37.8 & 262 & 62.2 & 58 & 30.7 & $\begin{array}{c}10 \\
0\end{array}$ & 63.3 & 0.164 \\
\hline $\begin{array}{l}\text { Kirmızı et } \\
\text { tüketimim artt1 }\end{array}$ & 311 & 53.7 & 268 & 46.3 & 223 & 53.0 & 198 & 47.0 & 88 & 55.7 & 70 & 44.3 & 0.492 \\
\hline $\begin{array}{l}\text { Çikolata ve tatlı gibi } \\
\text { şekerli gıda } \\
\text { tüketimim arttı }\end{array}$ & 377 & 65.1 & 202 & 34.9 & 292 & 69.4 & 129 & 30.6 & 85 & 53.8 & 73 & 46.2 & 0.001 \\
\hline $\begin{array}{l}\text { Un ve unlu mamul } \\
\text { tüketimim arttı }\end{array}$ & 399 & 68.9 & 180 & 31.1 & 308 & 73.2 & 113 & 26.8 & 91 & 57.6 & 67 & 42.4 & 0.002 \\
\hline $\begin{array}{l}\text { Sebze tüketimim } \\
\text { artt1 }\end{array}$ & 338 & 58.4 & 241 & 41.6 & 251 & 59.6 & 170 & 40.4 & 87 & 55.1 & 71 & 44.9 & 0.020 \\
\hline $\begin{array}{l}\text { Meyve tüketimim } \\
\text { artt1 }\end{array}$ & 393 & 67.9 & 186 & 32.1 & 286 & 67.9 & 135 & 32.1 & 107 & 67.7 & 51 & 32.3 & 0.091 \\
\hline
\end{tabular}

Tablo 4. COVID-19 kısıtlamaları sürecinde yetişkinlerin cinsiyetlere göre fiziksel aktivite ve algılanan stres düzeyleri

\begin{tabular}{|c|c|c|c|c|c|c|c|}
\hline Fiziksel Aktivite ve Alg1lanan Stres & \multicolumn{2}{|c|}{$\begin{array}{l}\text { Toplam } \\
(\mathrm{n}=579)\end{array}$} & \multicolumn{2}{|c|}{$\begin{array}{c}\text { Kadın } \\
(\mathrm{n}=421)\end{array}$} & \multicolumn{2}{|c|}{$\begin{array}{c}\text { Erkek } \\
(\mathrm{n}=158)\end{array}$} & \multirow[t]{2}{*}{$\mathrm{p}$} \\
\hline Fiziksel Aktivite Düzeyi & $\mathbf{n}$ & $\%$ & $\mathrm{n}$ & $\%$ & $\mathrm{n}$ & $\%$ & \\
\hline İnaktif & 313 & 54.1 & 237 & 56.3 & 76 & 48.1 & \multirow{3}{*}{0.147} \\
\hline Minimal aktif & 216 & 37.3 & 147 & 34.9 & 69 & 43.7 & \\
\hline Aktif & 50 & 8.6 & 37 & 8.8 & 13 & 8.2 & \\
\hline $\begin{array}{l}\text { Günlük oturularak geçirilen süre (saat) } \\
\text { (ort } \pm \text { ss) }\end{array}$ & \multicolumn{2}{|c|}{$6.50 \pm 4.34$} & \multicolumn{2}{|c|}{$6.36 \pm 4.20$} & \multicolumn{2}{|c|}{$6.87 \pm 4.49$} & 0.206 \\
\hline $\begin{array}{l}\text { Toplam Fiziksel Aktivite MET } \\
\text { (dk/hafta) (ort } \pm \text { ss) }\end{array}$ & \multicolumn{2}{|c|}{$928.93 \pm 1310.13$} & \multicolumn{2}{|c|}{$896.44 \pm 1333.0$} & \multicolumn{2}{|c|}{$\begin{array}{c}1015.50 \pm 1246 \\
.95\end{array}$} & 0.330 \\
\hline Alg1lanan Stres Düzeyi (ort \pm ss) & \multicolumn{2}{|c|}{$8.12 \pm 2.65$} & \multicolumn{2}{|c|}{$8.41 \pm 2.66$} & \multicolumn{2}{|c|}{$7.36 \pm 2.45$} & $<0.001$ \\
\hline
\end{tabular}




\section{TARTIŞMA}

Türkiye'de COVID-19 pandemisinin toplum sağlığ1 üzerindeki etkisini inceleyen önceki çalışmalar, salgının yaşam tarzı değişiklikleri üzerindeki etkisinden çok psikolojik etkisine odaklanmıştır. Bu çalışma, COVID-19 pandemisi kısıtlamalarının yetişkinlerin diyet davranışları, fiziksel aktivite ve stres düzeylerini değerlendirmeyi amaçlamıştır. COVID19 kısıtlamaları sirasında beslenme düzenindeki değişiklikler, daha düşük fiziksel aktivite ve yeni bir duruma uyum sağlamayla ilişkili stresin potansiyel olarak obezite, kardiyovasküler hastalıklar, osteoporoz, depresyon gibi sağlık risklerini artırdığ1 belirtilmektedir ${ }^{5,7,12,18}$.

Çalışmada kısıtlamalar sırasında katılımcıların yarısına yakının, kadınların ise yarısından fazlasının tüm günü kapalı ortamda geçirdiği belirlenmiştir. Ayrıca katılımcıların yarısından fazlasının inaktif olduğu bulunmuştur. Fiziksel aktivite düzeyi ile ilgili kadın ve erkeler arasında anlamlı bir fark görünmemesine rağmen erkeklerin kadınlara göre daha yüksek fiziksel aktivite düzeylerine sahip olduğu ve kadınların daha büyük bir kısmının inaktif olduğu belirlenmiştir. Ölüme sebep olan risk faktörleri arasında dördüncü sırada yer alan fiziksel inaktivite, tüm ölümlerin \%6'sının sebebi olarak gösterilmektedirr ${ }^{17}$. Sinırlı fiziksel aktivitenin, kardiyovasküler riski artıracak çeşitli metabolik etkilere sebep olduğu bilinmektedir. Düzenli fiziksel aktivite enflamasyonu ve bununla ilişkili hastalıkları azaltmakta, normal kilonun korunmasina ve visseral yağ birikiminin azaltılmasına katkıda bulunmaktadır ${ }^{18}$. Bulaşıcı olmayan hastalıkların önlenmesi için fiziksel aktivitenin zorunlu olduğunu belirten DSÖ, kısıtlamalar sırasında sağlık risklerini ortadan kaldırmak için haftada 150 dakika orta yoğunlukta veya 75 dakika şiddetli fiziksel aktivite veya her ikisinin bir kombinasyonunu önermiştir 9 . Ne yazık çalışmada kısıtlamalar sırasında bireylerin büyük bir kısmının bu seviyede bir fiziksel aktiflik göstermediği, yalnızca çok küçük bir kısmının aktif olarak değerlendirilebilecek fiziksel aktivite düzeyine sahip olduğu bulunmuştur. Pandemi koşullarında açık havada yapılan sosyal aktivitelerin yasaklanmasi ve spor salonlarının kapatılması fiziksel aktivite seviyesinin istenilen düzeyde olmamasının sebepleri olabilir. Ayrıca daha önce Türkiye'de yapılan Kronik Hastalıklar Risk Faktörleri Sıklığı Çalışmasında erkeklerin \%23'ünün kadınların ise yalnızca \%13'ünün fiziksel olarak aktif olduğu bulunmuştur ${ }^{25}$. Bu veriler Türk toplumunun fiziksel aktivite düzeyinin halihazırda oldukça düşük olduğunu ortaya koymaktadır. Kronik sedanter bir yaşam tarzının sağlık için zararlı olduğuna dair güçlü epidemiyolojik kanıtlar vardır. Bu tür olumsuz etkilerin fiziksel egzersiz programlarını yaparken bile devam ettiği için bunun önüne geçmek için egzersiz sürelerini uzatmanın yanı sıra oturma sürelerini azaltmanın da önemli olduğunu ortaya koymaktadır ${ }^{26}$. Çalışmada katılımcıların günün dörtte birini oturarak geçirdikleri dikkat çekicidir. İnsanların evde kalmasını zorunlu kılan kisıtlamaların bir sonucu olarak fiziksel aktivite ve egzersiz seviyelerinin önemli ölçüde düşmesi diyette değişiklik yaşanmasa bile pozitif bir enerji dengesi oluşturulmasına sebep olmakta ve bu durum kilo artışı ile sonuçlanabilmektedir. Çalışmada katılımciların yarısından fazlasinın kisitlamalar sırasında kilo artışı algılamasının sebebi bu pozitif enerji dengesi olabilir.

COVID-19 sürecinde beslenme alışkanlıklarında meydana gelen değişim incelendiğinde katılımcıların büyük bir kısmının sevdiği gıdaları daha fazla tüketme eğiliminde olduğu, yemekten sonra atıştırma sıklıklarının arttığı, cips, çerez, çikolata, tatlı, un ve unlu mamuller gibi yüksek düzeyde karbonhidrat ve yağ içeren gıdaların, çay ve kahve tüketiminin arttığ1 belirlenmiştir. Çalışmanın bu sonuçları COVID-19 kısıtlamaları sırasinda bireylerin beslenme eğilimlerinin değiştiğini göstermektedir. Bu değişim izolasyon tedbirleri sebebiyle evde geçirilen sürenin artması ve yemek pişirmek için daha fazla zaman ayrılması ile ilişkili olabilir. Farklı ülkelerde kısıtlamalar sırasında yetişkinlerin diyet davranışlarını inceleyen benzer çalışmalarda bireylerin izolasyon, uyaran eksikliği ve can sıkıntısı gibi nedenlerle beslenme rutinlerinin değiştiği ve diyetlerini yeterince kontrol edemedikleri bulunmuştur 5,11,20. Ayrıca çalışmalar yoğun stresli ve kaygılı durumlarda insanların durum ile daha iyi baş etmek için tipik tepki olarak daha fazla yeme eğiliminde oldukları ve enerji yoğunluğu yüksek çikolata, cips, çerez, fastfood gidalar gibi sağlıksız yiyecekleri tüketmeye yöneldiği göstermektedir ${ }^{18,27-29}$. Bireyler strese daha fazla yiyerek yanıt verdiklerinde, seçilen yiyeceklerin tipik olarak daha yüksek şeker ve yağ oranına sahip olduğu bildirilmektedir ${ }^{28,29}$. Çalışmada bireylerin yeme alışkanlıklarındaki değişimin bir diğer sebebi katılımcıların duygularını yemek yoluyla düzenleme eğiliminde olmalarından kaynaklanmış olabilir. Çalışmada kadınların algılanan stres seviyelerinin erkeklere oranla daha yüksek olması ve erkeklerden daha fazla çikolata, tatlı gibi şekerli gıda, un ve unlu mamul tüketmeleri bu bilgiyi destekler niteliktedir. 
Pandemi gibi ani gelişen felaketleri bir psikolojik kriz olarak değerlendirmek mümkündür ${ }^{30}$. Pandeminin doğasında yer alan belirsizlik ve korku bireylerin yoğun düzeyde stres ve kayg1 yaşamasina sebep olmaktadır ${ }^{13,14,19}$. Pandeminin sebep olduğu zorlu koşullarda, bireyler stresle baş etmek için daha fazla sosyal desteğe ihtiyaç duymalarına karşın izolasyon zorunluğundan dolayı sosyal destek sistemlerinden uzak kalmakta, kısıtlamalar nedeniyle günlük rutinlerin kesintiye uğraması, medyada s1k s1k pandemi ile ilgili kayg1 verici gelişmelerin paylaşılmasının bireylerin anksiyete ve stresini daha da artırmaktadır ${ }^{5,12-14,19}$. Yüksek düzeyde psikolojik stresin sempatik sinir sistemi aktivitesini ve buna bağl1 aterosklerotik ve iskemik kalp hastalığına bağlı ani kardiyak ölüm riskini artırdığ 1 bilinmektedir ${ }^{18}$. Bununla birlikte, mevcut durumda COVID-19'un psikolojik ve duygusal sonuçlarını doğru bir şekilde tahmin etmek zordur. Çalışma sonuçları bu açıdan incelendiğinde çalışmaya katılan bireylerde algılanan stresin orta düzeyde olduğu, özellikle kadınlarda stres düzeyinin erkeklere oranla anlamlı derecede yüksek olduğu bulunmuştur. Cinsiyetin, ruh sağllğ ve hastalıklarının önemli belirleyicilerinden olduğu bilinmektedir. Depresyon, anksiyete ve somatik şikayetlerin kadınlarda erkeklere oranla daha fazla görüldüğü vurgulanmaktadır ${ }^{31}$. Toplumsal rollerden dolayı bu süreçte kadınlar evde gereksinim duyulan bakımı daha fazla üstlenmektedir. Uzun süre evde kalmak ve aile üyelerinin bakım ihtiyacını karşılamaya çalışmak kadınların stres seviyelerinin artmasına katkı veren diğer faktörler olabilir. Bu sebeple özellikle kadınların pandemi sürecinde ve sonrasında hem fiziksel hem ruhsal sağlık sorunları açısından daha fazla risk altında olabileceği göz ardı edilmemelidir.

Sonuç olarak COVID-19 salgını kısa bir süre içinde küresel olarak bir acil durum yaratmıştır. Bu bulaşıcı virüs, yalnızca genel halk sağlığı konusunda endişelere yol açmakla kalmamış, aynı zamanda toplumun yaşam şeklinde ve alışkanlıklarında da birçok değişikliğe sebep olmuştur. Bu çalışmanın sonuçları COVID-19 kısıtlamaları sırasında yetişkin bireylerin büyük bir kısmı inaktif olduğunu ve algılanan stres seviyelerinin ortalamanın üzerinde olduğunu, yetişkinlerin diyet davranışlarının önemli ölçüde değiştiğini, riskli ve sağlıksız diyet davranışlarına eğilimin arttığını göstermektedir. Bu sonuçlar pandeminin olası ikinci ve üçüncü dalgaları için veya sosyal izolasyonun olduğu benzer durumlarda beslenme, fiziksel aktivite ve olası psikolojik etkilere yönelik alınabilecek önlemlerin ve sekonder hastalık riskini en aza indirmeye hedefleyen stratejilerin belirlenmesinin ve güçlendirilmesinin önemini ortaya koymaktadır. Buna rağmen çalışmanın bazı sınırlıkları bulunmaktadır. Bu sinırlıklarından biri katılımcıların öz bildirimlerinin dikkate alınması ve COVID-19 süreci öncesindeki beslenme alışkanlıkları, fiziksel aktivite ve stres düzeylerinin bilinmemesidir. İkinci bir sınırlılık, pandemi koşulları sebebiyle örnekleme sosyal medya platformları kullanılarak erişilmesi ve uzaktan veri toplanmış olmasıdır. Bu durum sosyal ağları ve teknolojiyi kullanabilen belirli bir grubun örneklenme alınmasına sebep olmuştur. Bu sebeple çalışmaya katılanları büyük oranda kadınlar ve eğitim seviyesi yüksek bireyler oluşturmuştur. Örneklem Türkiye'deki yetişkin nüfusun tam bir temsili olmadığ1 için çalışmanın sonuçlarının tüm topluma genellenemez.

\footnotetext{
Yazar Katkıları: Çalışma konsepti/Tasarımı: GEY, GM; Veri toplama: GEY, GM; Veri analizi ve yorumlama: GEY, GM; Yazı taslağı: GEY, GM; İçeriğin eleştirel incelenmesi: GEY, GM; Son onay ve sorumluluk: GEY, GM; Teknik ve malzeme desteği: -; Süpervizyon: GEY, GM; Fon sağlama (mevcut ise): yok.

Etik Onay: Bu çalışma için Nevşehir Hacı Bektaş Veli Üniversitesi Etik Kurulundan 08.02.2020 tarih ve 2020.12.127 sayll kararı ile etik onay alınmıştır.

Hakem Değerlendirmesi: Dış bağımsız.

Cıkar Catıșması: Yazarlar çıar çatısması beyan etmemişlerdir.

Finansal Destek: Yazarlar finansal destek beyan etmemişlerdir.

Author Contributions: Concept/Design : GEY, GM; Data acquisition: GEY, GM; Data analysis and interpretation: GEY, GM; Drafting manuscript: GEY, GM; Critical revision of manuscript: GEY, GM; Final approval and accountability: GEY, GM; Technical or material support: -; Supervision: GEY, GM; Securing funding (if available): $\mathrm{n} / \mathrm{a}$.

Ethical Approval: Ethical approval was obtained for this study from the Ethics Committee of Nevşehir Hacı Bektaş Veli University with the decision dated 08.02.2020 and numbered 2020.12.127.

Peer-review: Externally peer-reviewed.

Conflict of Interest: Authors declared no conflict of interest.

Financial Disclosure: Authors declared no financial support
}

\section{KAYNAKLAR}

1. TC Sağllk Bakanlı̆̆ı COVID-19 Nedir? https://covid19bilgi.saglik.gov.tr/tr/covid-19-yenikoronavirus-hastaligi-nedir.html (accessed sep 2020).

2. World Health Organization. Coronavirus disease (COVID-19) pandemic. https://www.euro.who.int/en/health-topics/healthemergencies/coronavirus-covid-19/novelcoronavirus-2019-ncov (accessed sep 2020).

3. Zhu N, Zhang D, Wang W, Li X, Yang, B, Song J et al. A novel coronavirus from patients with pneumonia in China, 2019. N Engl J Med. 2020;382:727-33.

4. Hossain MM, Sultana A, Purohit N. Mental health outcomes of quarantine and isolation for infection prevention: A systematic umbrella review of the global evidence. Epidemiol Health. 2020;42:e2020038.

5. Ammar A, Brach M, Trabelsi K, Chtourou H, Boukhris O, Masmoudi L. Effects of COVID-19 home confinement on eating behaviour and Physical 
activity: results of the ECLB-COVID19 International Online Survey. Nutrients. 2020;12:1583.

6. Hu Z, Lin X, Kaminga AC, Xu H. Impact of the COVID-19 epidemic on lifestyle behaviors and their association with subjective well-being among the general population in mainland china: cross-sectional study. J Med Internet Res. 2020;22:e21176.

7. Antunes R, Frontini R, Amaro N, Salvador R, Matos R, Morouço P et al. Exploring lifestyle habits, physical activity, anxiety and basic psychological needs in a sample of portuguese adults during COVID-19. Int J Environ Res Public Health. 2020;17:4360.

8. Hammami A, Harrabi B, Mohr M, Krustrup P. Physical activity and coronavirus disease 2019 (COVID-19): specific recommendations for homebased physical training. Managing Sport and Leisure. 2020;1-6.

9. World Health Organization. Stay physically active during self-quarantine. https://www.euro.who.int/en/health-topics/healthemergencies/coronavirus-covid-19/technicalguidance/stay-physically-active-during-selfquarantine (accessed sep 2020).

10. World Health Organization. Food and Nutrition during Self-Quarantine: What to Choose and How to Eat Healthy. https://www.euro.who.int/en/healthtopics/health-emergencies/coronavirus-covid19/technical-guidance/food-and-nutrition-tipsduring-self-quarantine (accessed sep 2020).

11. Martinez-Ferran M, de la Guía-Galipienso F, SanchisGomar F, Pareja-Galeano H. Metabolic impacts of confinement during the COVID-19 pandemic due to modified diet and physical activity habits. Nutrients. 2020;12:1549.

12. Todisco P, Donini LM. Eating disorders and obesity $(\mathrm{ED} \& O)$ in the COVID-19 storm. Eat Weight Disord. 2020;1:1-4.

13. Brooks SK, Webster RK, Smith LE, Woodland L, Wessely S, Greenberg N, et al. The psychological impact of quarantine and how to reduce it: rapid review of the evidence. Lancet. 2020;395:912-20.

14. Salari N, Hosseinian-Far A, Jalali R, Vaisi-Raygani A, Rasoulpoor S, Mohammadi M. Prevalence of stress, anxiety, depression among the general population during the COVID-19 pandemic: a systematic review and meta-analysis. Global Health. 2020;16:1-11.

15. Lippi G, Sanchis-Gomar F. An estimation of the worldwide epidemiologic burden of physical inactivity-related ischemic heart disease. Cardiovasc Drugs Ther. 2020;34:133-7.

16. GBD 2015 Risk Factors Collaborators. Global, regional, and national comparative risk assessment of 79 behavioural, environmental and occupational, and metabolic risks or clusters of risks, 1990-2015: a systematic analysis for the Global Burden of Disease Study 2015. Lancet. 2016; 388:1659-724.

17. World Health Organization. Noncommunicable diseases country profiles 2018. https://www.who.int/nmh/publications/ncdprofiles -2018/en/ (accessed sep 2020).

18. Mattioli AV, Nasi M, Cocchi C, Farinetti A. COVID 19 outbreak: impact of the quarantine-induced stress on cardiovascular disease risk burden. Future Cardiol. 2020; doi: 10.2217 /fca-2020-0055.

19. Zhang J, Lu H, Zeng H, Zhang S, Du Q, Jiang T, et al. The differential psychological distress of populations affected by the COVID-19 pandemic. Brain Behav Immun. 2020;87:49-50.

20. Di Renzo L, Gualtieri P, Cinelli G, Bigioni G, Soldati $\mathrm{L}$, Attinà $\mathrm{A}$ et al. Psychological aspects and eating habits during COVID-19 home confinement: Results of EHLC-COVID-19 Italian Online Survey. Nutrients. 2020;12:2152.

21. Craig CL, Marshall AL, Sjöström M, Bauman AE, Booth ML, Ainsworth BE et al. International physical activity questionnaire: 12-country reliability and validity. Med Sci Sports Exerc. 2003;35:1381-95.

22. Öztürk M. Üniversitede eğitim-öğretim gören ögrencilerde Uluslararası Fiziksel Aktivite Anketinin geçerliği ve güvenirliği ve fiziksel aktivite düzeylerinin belirlenmesi. [Bilim uzmanlığı tezi]. Ankara: Hacettepe Üniversitesi, 2005.

23. Cohen S, Kamarck T, Mermelstein R. A global measure of perceived stress. J Health Soc Behav. 1983;24:385-96.

24. Eskin M, Harlak H, Demirkıran F, Dereboy Ç. Algılanan Stres Ölçeği’nin Türkçeye uyarlanması: güvenirlik ve geçerlik analizi. Yeni Symposium. 2013;51:132-40.

25. TC Sağlık Bakanlığı. Türkiye Bulaşıc1 olmayan hastalıklar çok paydaşlı eylem planı, 2017-2025. Ankara, Sağlık Bakanlığı, 2017. .

26. Biswas A, Oh PI, Faulkner GE, Bajaj RR, Silver MA, Mitchell MS et al. Sedentary time and its association with risk for disease incidence, mortality, and hospitalization in adults a systematic review and metaanalysis. Ann. Intern. Med. 2015;162:123-32.

27. Braden A, Musher-eizenman D, Watford T, Emley E. Eating when depressed, anxious, bored, or happy: Are emotional eating types associated with unique psychological and physical health correlates? Appetite. 2018;125:410-7.

28. İnalkaç S, Arslantaş H. Duygusal yeme. Arşiv Kaynak Tarama Dergisi. 2018;27:70-82.

29. Serin Y, Şanlıer N. Duygusal yeme, besin alımını etkileyen faktörler ve temel hemşirelik yaklaşımları. J Psychiatric Nurs. 2018;9:135-46.

30. Xiang YT, Yang Y, Li W, Zhang L, Zhang Q, Cheung $\mathrm{T}$, et al. Timely mental health care for the 2019 novel coronavirus outbreak is urgently needed. Lancet Psychiatry. 2020;7:228-9.

31. World Health Organization (WHO) Gender and women's mental health: Gender disparities and mental health: The Facts 2020. Available online: https://www.who.int/mental_health/prevention/ge nderwomen/en/ (accessed oct 2020). 